\title{
JÚLIO RIBEIRO, O NATURALISMO E A DESSACRALIZAÇÃO DA LITERATURA
}

Leonardo Pinto MENDES (Universidade do Estado do Rio de Janeiro) leonardomendes@utexas.edu

RESUMO: A hipótese desse estudo é que a hostilidade da tradição crítica à ficção naturalista, e especialmente ao romance $A$ carne (1888), de Júlio Ribeiro (18451890), encobria o apego a uma concepção sagrada de homem e de literatura, de raiz romântica, que informava a série histórica das críticas à obra do autor, de José Verissimo aos dias de hoje. Para a tradição crítica, o intolerável era a perda da sacralidade da literatura, que no romance naturalista era rebaixada e retalhada por discursos concorrentes e novos gêneros textuais.

Palavras-chave: Júlio Ribeiro. Naturalismo. Materialismo. Historiografia.

\section{JÚLIO RIBEIRO, NATURALISM AND THE DOWNGRADING OF LITERATURE}

ABSTRACT: The hypothesis of this study is that the critical tradition's hostility towards naturalist fiction, and especially towards Júlio Ribeiro's novel $A$ carne (1888), emanated from the fury over the loss of men's and literature's sacred status, from José Verissimo to present day. This loss was thought to be unbearable, as it downgraded literary discourse, as well as slashed it with competing discourses and new literary genres.

Keywords: Júlio Ribeiro. Naturalism. Materialism. Historiography. 


\section{Introdução}

É difícil encontrar críticas positivas ao escritor Júlio Ribeiro (1845-1890) e sua obra. As que existem são ligadas aos rituais das agremiações literárias, como a saudação de Manuel Bandeira ao tomar posse na Academia Brasileira de Letras (BANDEIRA, 2002), e a biografia de José Aleixo Irmão (s/d), do Instituto Histórico e Geográfico de São Paulo. De resto, há uma montanha de críticas negativas ao autor, e especialmente ao romance naturalista $A$ carne, que ele publicou em São Paulo em 1888. O romance teve a carreira dos "livros malditos", julgado obra inferior por José Veríssimo (1894), Álvaro Lins (1963), Lúcia Miguel Pereira (1988), Brito Broca (1991), Josué Montello (1986), José Guilherme Merquior (1979) e Alfredo Bosi (1972), para citarmos os críticos mais conhecidos.

Por que uma obra mal falada aparece nos manuais de história da literatura? Afinal, aparecer nos manuais é sinal de distinção, se nos lembrarmos das dezenas de escritores fracassados e ignorados pela historiografia. Também é preciso atentar para o gesto de reconhecimento dos fundadores da $A B L$ (entre os quais havia escritores naturalistas), quando escolheram Júlio Ribeiro para patrono da cadeira de número vinte e quatro, logo depois de sua morte. Mas era um acolhimento ambíguo, porque escritores influentes como José Verissimo (18571916) e Machado de Assis (1839-1908) opunham resistência à estética naturalista. A leitura da série histórica de críticas ao romance de Júlio Ribeiro revela a reciclagem do posicionamento resistente de Machado e Verissimo ao naturalismo e a uma concepção materialista de mundo.

Nosso objetivo é estudar o argumento detrator do romance de modo a compreender o porquê da resistência à obra. Vamos tomar a crítica de Lucia Miguel Pereira (1901-1959) ao romance como paradigmática dessa tradição, no seu livro Prosa de ficção (1870-1920): História da literatura brasileira, cuja primeira edição é de 1950. A crítica não só resume bem o argumento consensual sobre o naturalismo, como também revela boa pesquisa de obras e autores da estética, das mais completas em manuais de literatura brasileira. Pereira é boa leitora do naturalismo brasileiro, e especialmente do romance Bom-Crioulo (1895), de Adolfo Caminha (1867-1897), que ela foi uma das primeiras críticas de renome 
a destacar. A esse ela junta O cortiço (1890), de Aluísio Azevedo (1857-1913), como o outro romance naturalista brasileiro de destaque.

Lucia Miguel Pereira, entretanto, julga bem realizados os dois romances apesar do naturalismo, pois para ela o naturalismo literário era um equívoco. Bom-Crioulo e $O$ cortiço eram bons romances porque escapavam à moldura naturalista. Pereira tende a ver o naturalismo como uma estética estrangeira ao romance brasileiro; era, como o parnasianismo, uma moda importada de Paris. $O$ racionalismo, o ateísmo e o materialismo da inteligência brasileira (que ocorrem a partir de 1870), via o cientificismo e o positivismo (ALONSO, 2002; MELLO, 2007), tiveram vago impacto no romance brasileiro do final do século XIX, pensa Pereira. A ideia de que tanto o naturalismo quanto o parnasianismo foram estéticas mais ou menos malogradas tem sido um lugar-comum da historiografia desde o modernismo.

Nosso hipótese é que a resistência ao romance naturalista visava preservar o vínculo da literatura (e dos escritores) com a dimensão do sagrado, que vinha do imaginário romântico. No naturalismo a literatura era "rebaixada", sexualizada, banalizada e retalhada por discursos concorrentes (sendo o cientificismo o mais notório) e novos gêneros textuais, muitos ligados à imprensa diária, tais como a reportagem, o folhetim e o fait divers (BAGULEY, 1990). Júlio Ribeiro e outros escritores naturalistas eram homens da imprensa. Vivia-se uma condição peculiar ao século XIX: a "coincidência essencial" entre dois sistemas profissionais, que fazia com que as mesmas pessoas circulassem nos campos jornalístico e literário (THÉRENTY, 2007, p. 18). O impacto dos gêneros jornalísticos na prosa naturalista brasileira ainda aguarda para ser estudado.

Lucia Miguel Pereira desenvolve o argumento a partir de ideias-chave que reciclam os posicionamentos de Machado e Verissimo, assim como fazem os críticos anteriores e posteriores a ela. Cada ideia circunscreve um aspecto do romance de Júlio Ribeiro (e da estética naturalista) que rompia com uma concepção sagrada (ou romantizada) de literatura. Vamos destacar quatro ideiaschave que serão analisadas de forma mais detida, sem esquecer que elas se sobrepõem e se interpenetram. Ao longo da exposição traremos reverberações dessas ideias em outros críticos, sem a pretensão de ser exaustivo e sem preocupação com a cronologia. 
Adotamos uma concepção ampliada de naturalismo como estética da civilização industrial do século XIX, destemida do paradoxo, capaz de acomodar subgêneros, apropriações, vertentes e modos de execução estranhos à historiografia tradicional (BAGULEY, 1990), mas que eram reconhecidos como "naturalistas" no momento de sua primeira circulação. Nossa meta é compreender o romance de Júlio Ribeiro nos termos do paradigma materialista da modernidade do século XIX. Propomos uma nova historiografia do naturalismo no Brasil à luz de novas fontes e teorias. Esse estudo sobre o romance $A$ carne é uma contribuição.

\section{A escravização ao concreto}

Lucia Miguel Pereira usa a expressão "a escravização ao concreto” (p. 135) para criticar o "fatalismo" que mecanizava os conflitos do romance naturalista e cerceava a liberdade dos personagens. O argumento era que a ficção naturalista reduzia o homem a um mamífero submetido aos mesmos processos de outros organismos vivos. Em atenção a esses processos, que começavam a ser conhecidos, os escritores naturalistas estreitavam 0 raio de ação dos personagens, porque do ponto de vista materialista as pessoas eram corpos capazes de grandes coisas, mas não de qualquer coisa. Se toda vida emanava de um corpo material e mortal, ela se desenvolvia dentro dos limites definidos pela história deste corpo físico.

Os limites físicos podiam ter vários nomes: desejo, instinto, fome, doença, hábitos culturais, morte ou hereditariedade genética, entre outros. Todo homem trazia inscrito em seu corpo uma história, que incluía a história de seus antepassados, nas heranças genéticas (favoráveis ou desfavoráveis) que determinavam suas formas e capacidades físicas, assim como no ambiente físico (no meio) em que nasceram e cresceram. Para os escritores naturalistas, tratavase de compreender que havia vários fatores que determinavam, para o bem e para o mal, a vida das pessoas. As capacidades físicas podiam ser expandidas e melhoradas, mas dependendo de onde vieram e de como eram, havia limites para o que as pessoas podiam ser e fazer. Essa moldura, que os escritores 
naturalistas tomavam como dado incontornável da realidade, é chamada por Pereira de "escravização ao concreto".

A expressão "escravização ao concreto" revela a crença na excepcionalidade do homem e a resistência às teorias darwinistas. A expressão rejeita a tese naturalista de que só se podia compreender o homem quando se compreendia seu lugar na natureza - que não existia outro lugar para ele viver, fora ou além da natureza, e que nem a cultura, a tecnologia ou a consciência (o cogito de Descartes) poderiam retirá-lo desse lugar (PHILLIPS, 2000). Pereira percebe o materialismo como uma forma de aprisionamento e trabalha com uma concepção platônica do humano que ultrapassa os limites do corpo físico. Ela faz uma aposta na existência de algo além, uma dimensão metafísica da existência humana, que a define e explica. Esse além remetia ao domínio do sagrado.

A hostilidade ao materialismo e o apego a uma concepção sagrada de existência (e de literatura) são a base de onde emanam as críticas à ficção naturalista no Brasil. Em 1878 Machado de Assis tinha explicado, na célebre resenha a O primo Basílio (1878), de Eça de Queirós (1845-1900), que tratava-se "de repelir a doutrina, e não o talento, e menos o homem" (ASSIS, 1997, p. 904). A "doutrina" incluía a episteme moderna, materialista e cientificista, e notadamente o darwinismo. Tratava-se, portanto, de rejeitar o materialismo como sistema filosófico. Escrevendo sobre o romance naturalista, José Veríssimo condenou os escritores "que considera[va]m o homem uma espécie de organismo físico inteiramente dominado por leis fisiológicas iniludíveis" (VERISSIMO, 1894, p. 20). Lucia Miguel Pereira, na mesma linha, lamentou que em Bom-Crioulo os personagens fossem "corpos apenas" (PEREIRA, 1988, p. 168).

A crítica ao "reducionismo" era uma negação do desamparo do apenas, do nada mais, e implicava a busca de algo mais, que distinguia o homem dos outros animais. Do ponto de vista materialista, entretanto, esse algo mais não passava de uma fantasia, que ao idealizar e sacralizar a existência humana, só fazia falsificá-la e degradá-la, como se ter um corpo físico fosse algo desprezível. A opinião de que era degradante supor que a única vida que existia era a vida do corpo só podia vir de pessoas que achavam o corpo degradante. Do ponto de vista materialista, as descrições do romance naturalista só seriam degradantes se lidas a partir de uma concepção idealizada do humano, que apostava na 
transcendência e no sagrado porque rejeitava o desamparo do nada mais - não havia um criador e tampouco algum desígnio (ou lugar privilegiado para o homem) na natureza (PHILLIPS, 2000 \& 2011).

\title{
2. A personagem Lenita é falsa
}

A acusação de inverossimilhança foi das mais frequentes ao naturalismo. Era uma acusação surpreendente, se nos lembrarmos do vínculo da estética com o método científico e o combate às ilusões. Mas para os homens de letras, era inacreditável que existisse na década de 1880 uma moça como Lenita. Não era possível que uma moça de vinte e dois anos fosse tão culta e independente. $E$ mais: não era possível que uma moça de sua posição praticasse sexo oral na mata e falasse com homens sobre menstruação. Escreve Pereira: "Lenita é tão inexistente, com o seu corpo demasiadamente exigente, como as incorpóreas heroínas românticas" (p. 131). Lenita era falsa porque não havia corpos exigentes como o dela.

Era a mesma opinião de José Verissimo:

\begin{abstract}
Nada explica as suas ações [de Lenita], é impossível compreendê-la, apesar de nada haver de complexo em seu caráter. Vai ao quarto de um homem relativamente velho, casado e que ainda não é seu amante, como uma mucama desbriada de fazenda, e sujeita-se depois aos seus caprichos de uma grosseira e bestial sensualidade, como a última das rameiras (VERISSIMO, 1894, p. 20).
\end{abstract}

Verissimo lista o inverossímil: uma moça culta e rica toma a iniciativa de ir ao quarto de um homem casado para ter relações sexuais. Comporta-se desse modo como uma "mucama desbriada de fazenda". No quarto, Lenita faz algo inacreditável: "sujeita-se" aos caprichos do homem. Na sociedade que Verissimo frequentava, as mulheres de respeito resistiam aos caprichos do homem. Talvez ele fosse sincero quando revela que o único sexo que conhecia entre pessoas de distinção era o sexo contido, exilado do corpo e do prazer. Na literatura, o sexo das classes dominantes seria mais bem representado pelas lacunas ou pontos de exclamação dos romances de Machado de Assis. O sexo de Lenita, pensa Verissimo, era como aquele praticado nas senzalas. 
O ponto de vista do romance, entretanto, era de que a natureza não tinha classe social. Os corpos podiam ser feios ou bonitos, ricos ou pobres, mas eram todos exigentes e mortais. Em $O$ cortiço, Aluísio desenvolveu essa ideia na personagem D. Estela, que era rica, mas gostava de sexo "bestial" (MENDES, 2000). A regra, no entanto, foi focar o corpo das classes subalternas, como vemos nos marinheiros de Bom-Crioulo. Percebido como chocante e degradante, esse corpo era, aos olhos da elite letrada que comprava e lia livros, o corpo de um outro. Nesse contexto, A carne, assim como o romance $O$ homem (1887), de Aluísio Azevedo, devem ter sido especialmente perturbadores por terem como foco os corpos das elites. $O$ homem e $A$ carne são romances que falam sobre a sexualidade de uma moça branca e rica. Ambos são mal avaliados pela historiografia.

O mesmo argumento da inverossimilhança foi desenvolvido pelo padre José Joaquim de Sena Freitas (1840-1913). Como era um radical, Sena Freitas traz para a superfície do texto a base idealizadora de onde partiam as restrições ao naturalismo. Escreve o crítico: "Não é nada natural que uma donzela honesta, virgem como a supõe o autor, educada esmeradamente por seu pai, estreie em sexualidade erótica pelo meretrício, e tomando por duas vezes a atitude do homem" (FREITAS \& RIBEIRO, s.d., p. 35). Como José Verissimo, Sena Freitas supunha inverossímil uma sexualidade feminina autônoma, que era uma das teses defendidas no romance. Tanto Lenita quanto Manduca se declaram a favor do amor livre e do divórcio. Num arroubo de independência, a moça imagina ser capaz de manter relações passageiras com vários homens, "tomar dez, vinte, cem amantes" (RIBEIRO, 2002, p. 116).

No século XIX, o único nome que os críticos dispunham para descrever uma moça assim era "rameira" ou "meretriz". A quebra de protocolo (Lenita toma a iniciativa de ir ao quarto de Manduca) expressava uma autonomia intolerável para Veríssimo e Sena Freitas. Para o padre, viabilizar um encontro sexual era uma prerrogativa masculina. A autonomia sexual da protagonista era uma das várias facetas antipatriarcais de $A$ carne. A impressão de que Lenita assumia papéis masculinos era confirmada pelo romance, que a descreve como uma moça destemida, independente e "viril" (RIBEIRO, 2002, p. 73), a ponto de o coronel 
Barbosa lhe dizer que ela "devia ter nascido homem... e quem sabe se ela não [era] mesmo homem" (RIBEIRO, 2002, p. 185).

Do ponto de vista da crítica tradicional, a falsidade de Lenita resultava do equívoco naturalista de supor o corpo físico superior à vida moral. A ideia de que o corpo tinha suas próprias necessidades e podia agir por razões próprias, independente de decoro, posição e estudo, repugnava Machado de Assis. Daí vinha a acusação frequente de que os personagens naturalistas agiam por instinto e eram criaturas sem alma, fantoches ou meros tipos, sem profundidade psicológica. Escreveu Machado sobre O primo Basílio: Luísa "é antes um títere do que uma pessoa moral" (p. 905). E ainda: "Luísa resvala no lodo, sem vontade, sem repulsa, sem consciência; Basílio não faz mais do que empuxá-la, como matéria inerte, que é" (p. 905).

\section{0 pedantismo cientificista}

Lucia Miguel Pereira chama de "pedantismo cientificista" (p. 132) a intromissão da ciência na literatura. A parceria do romance naturalista com 0 discurso científico nunca foi vista com bons olhos. No Brasil, mesmo escritores que abraçaram a estética, como Aluísio Azevedo e Adolfo Caminha, tinham dúvidas sobre o lugar da ciência na literatura. Quando escreveu seu romance mais científico, O homem, Aluísio contou com a assessoria de um estudante de medicina (FLAVIO, 1920). Lucia Miguel Pereira se refere à obra como "escuso atalho", pois o apelo à ciência era um erro de concepção artística. No romance, entretanto, o dono do discurso científico, o doutor Lobão, aparece como uma figura pedante e ridícula. Nessa mesma época, Aluísio teria argumentado que um "romance não [era] uma dissertação inaugural de medicina" (apud FLAVIO, 1920, p. 17). Adolfo Caminha, por seu turno, se irritava com o excesso de termos científicos do romance de Zola e julgava a hereditariedade fisiológica "um fato relativo" (CAMINHA, 1999, p. 41). Aparentemente nenhuma dessas relativizações impediu que o naturalismo entrasse para a história da literatura brasileira como a estética que sucumbiu aos ditames da ciência do segundo oitocentos.

De fato, as relações do romance naturalista com o discurso científico eram mais complexas do que dá a entender a historiografia. Independente dos usos e 
abusos dos princípios científicos no romance naturalista, a crença dos escritores era de que a literatura não podia ficar imune aos impactos da revolução tecnológico-científica do século XIX. A ciência afetou profundamente a arte do oitocentos e forneceu à ficção um discurso de autoridade que podia defendê-la dos ataques dos moralistas, assim como justificar uma enunciação impessoal e objetiva, como alternativa ao narrador deísta, onipotente e onipresente do romance realista tradicional. O narrador naturalista buscava ser impessoal e objetivo, mas sem onipotência e onipresença. O cientista era um cético, explicou Zola no ensaio "O romance experimental" (1880). A analogia com a ciência era ideal para os objetivos dos escritores de criar um novo gênero de prosa de ficção - uma literatura científica -, que liberava o escritor das convenções literárias do passado (BAGULEY, 1990).

Quando acusados de imorais, os escritores podiam argumentar que do ponto de vista científico, os fatos não eram morais nem imorais; eles simplesmente eram. No Brasil, assim fez Adolfo Caminha. Atacado pelo audacioso Bom-Crioulo, o escritor convidou seus críticos a visitar sua biblioteca, onde poderiam consultar uma alentada bibliografia científica, em francês, que justificava e documentava um romance sobre um marinheiro negro e gay (CAMINHA, 1896). Na resenha a favor de seu romance de estreia, $A$ normalista (1893), Caminha defendeu o método científico e a legitimidade do gênero romanesco para falar com objetividade das funções corporais (CAMINHA, 1999). Mas esse posicionamento materialista encontrava resistência. O próprio Caminha nutriu alhures a concepção idealizada da arte como um "maravilhoso templo" onde só se podia entrar "com o respeito e a convicção de sacerdotes impolutos" (CAMINHA, 1999, p. 18), num vocabulário religioso que defendia o estatuto sagrado da literatura. Isso mostrava como era difícil, até mesmo para os escritores naturalistas, romper com uma concepção romântica de arte (MENDES, 2012).

Tal concepção favorecia a ideia de que a presença do discurso científico na literatura era ao mesmo tempo uma profanação e uma degradação. Tendo em mente as obras do escritor cearense Rodolfo Teófilo (1853-1932), Lucia Miguel Pereira explicou que a preocupação científica do romance naturalista "representou um pesado fator antiartístico" (p. 135). Desse ponto de vista, a 
ciência despia a literatura de sua dimensão artística, deixando claro que ciência e arte eram domínios excludentes. Na opinião de Pereira, sem esconder suas inclinações românticas, "o artista, por mais que se esforce, não se pode conduzir como um bom homem de ciência. O seu domínio é mais a sensibilidade do que o raciocínio" (p. 128).

A chamada "poesia científica", que no Brasil foi defendida por Silvio Romero (1851-1914) e notadamente por José Isidoro Martins Júnior (1860-1904), nunca foi levada a sério e nem aparece na historiografia. Não seria exagero dizer que muitos escritores consideravam a ideia de uma "poesia científica" uma contradição em termos. Em 1878, Machado de Assis havia defendido a superioridade da "arte pura", onde não havia lugar para as minúcias técnicas, excessivas e obscenas, do romance naturalista (ASSIS, 1997, p. 908). Como Lucia Miguel Pereira, José Veríssimo havia sido da opinião de que Rodolfo Teófilo devia desbastar seus romances da "terminologia científica" (VERISSIMO, 1901, p. 264).

Pois $A$ carne era um romance inundado por terminologias e teorias científicas. No capítulo III, o narrador explica que "a menstruação [era] uma muda epitelial do útero, conjunta por simpatia com a ovulação, e que o terrorífero e caluniado corrimento [era] apenas uma consequência natural dessa muda" (RIBEIRO, 2002, p. 82). Quando da picada de cascavel no pé de Lenita, no capítulo XIII, Manduca dá uma aula sobre o sistema de circulação sanguínea, sobre as infecções por veneno ofídico, seus efeitos e tratamentos, com citação de fontes, tais como o cientista francês Claude Bernard (1813-1878), autor de Introduction à l'étude de la medicine expérimentale (1865), do qual Zola partiu para teorizar sobre o romance experimental.

O ponto de vista científico não se esgotava na biologia. Ele aparecia em estudos das condições climáticas do litoral paulista, na longa descrição geográfica e geológica da planície santista, na elucidação da engenharia da construção de pontes na província, assim como na apresentação detalhada e técnica do processo de moagem de cana-de-açúcar. Ao longo do romance dezenas de espécies da fauna e flora da mata atlântica eram descritas e classificadas, com seus nomes em latim. A ciência permeava de tal modo o romance, que a chegada à fazenda de um livro científico novo, o Exposé sommaire des théories 
transformistes de Lamarck, Darwin et Haeckel (1886), de Arthur Vianna de Lima, foi ocasião para Lenita e Manduca passarem uma noite romântica juntos, compartilhando a leitura até o amanhecer.

É fácil compreender por que um romance como este seria mal recebido pela instituição literária. Mesmo após mais de um século de sua publicação, quando parte do vocabulário científico já foi incorporado ao cotidiano, o romance ainda causa estranhamento. Sua ciência parece excessiva e pedante, como classificou Lucia Miguel Pereira. Mas para os escritores naturalistas, o discurso científico era uma forma de desmistificar e banalizar os fatos do cotidiano, incluindo a fisiologia humana. Ele fornecia um vocabulário novo que a ficção não devia ignorar. E ele permitia afirmar e sustentar a tese libertadora (especialmente para as mulheres) de que a ninfomania e a histeria surgiam da repressão sexual e da manutenção de "uma castidade impossível" (RIBEIRO, 2002, p. 110).

\section{A confusão entre observar e inventariar}

Para Lucia Miguel Pereira, a incompatibilidade entre o artista e o cientista causava a confusão entre observar e inventariar. Para o artista, "o pormenor só vale na medida em que auxilia a compreensão das personagens, é, a bem dizer, como que um prolongamento destas, um elemento da composição, e nunca o seu fito principal" (PEREIRA, 1988, p. 132). A introdução do ponto de vista científico na literatura produzia um efeito devastador: ele transformava o romance num "relatório" de miudezas sem relação direta com a ficção. Os "pormenores" adquiriam vida própria; quebrava-se a harmonia do conjunto da obra. Machado de Assis havia expressado a mesma opinião em 1878, na resenha de $O$ primo Basílio:

\footnotetext{
A gente de gosto leu com prazer alguns quadros, excelentemente acabados, em que o Sr. Eça de Queirós esquecia por minutos a preocupação da escola; e, ainda, nos quadros que Ihe destoavam, achou mais de um rasgo feliz, mais de uma expressão verdadeira; a maioria, porém, atirou-se ao inventário. Pois que havia de fazer a maioria, senão admirar a fidelidade de um autor, que não esquece nada, e não oculta nada? Porque a nova poética é isso, e só chegará à perfeição no dia em que nos disser o número exato dos fios de que se compõe um lenço de cambraia ou um esfregão de cozinha (ASSIS, 1997, p. 904).
} 
Ao reduzir o gênero romanesco a um "inventário", o naturalismo explicitava seu caráter "antiartístico". Daí viria a "monotonia das obras" naturalistas (PEREIRA, 1988, p. 136).

De fato, A carne era um romance estranho, de leitura difícil, entrecortado por uma série de discursos e gêneros textuais, interrompido abruptamente por listas e inventários, assim como por breves tratados científicos. O padre Sena Freitas explicitou seu espanto:

\begin{abstract}
A urdidura de $A$ carne é tão pouco complicada que nem propriamente se the pode chamar romance. Como enredo é frouxo, e a cada passo entrecortado. As descrições episódicas ocupam uma parte tão considerável do entrecho, que parecem querer sufocá-lo ou cobrirIhe a penúria. Essas descrições, aliás surpreendentes de verdade e de luxo de linguagem, podiam ter lugar mais idôneo no rodapé de um jornal ou em livro de viagens. Ainda de permeio com o ligamento do romance há páginas perfeitamente didáticas que estão clamando, a meter dó, por um compêndio de fisiologia, ainda quando o autor, por modéstia de Júlio Ribeiro, fosse D. Lenita, e não ele (FREITAS \& RIBEIRO, s.d., p. 35).
\end{abstract}

Aí estava o problema: $A$ carne não era "propriamente" um romance. Sena Freitas identifica pelo menos dois gêneros estranhos ao romanesco: o relato de viagem e o compêndio de fisiologia. Os dois gêneros impunham um regime textual descritivo estranho ao romance, que era assim despido de sua narratividade característica (BAGULEY, 1990; CATHARINA, 2005). A carne continha, ainda, outras narrativas de gêneros variados, não necessariamente interconectadas, que incluía o estudo de caso de histeria feminina (a que muitas vezes a historiografia reduziu o romance), panfletos de oposição ao latifúndio escravocrata paulista, catálogos de objetos de arte e da fauna e flora da mata atlântica, reportagens sobre a ferrovia Santos-Jundiaí, além de libelo pelo separatismo paulista. Com efeito, para Oswald de Andrade (1890-1954), A carne era mais uma "aventura intelectual" do que um romance propriamente dito (1952, p. 177).

\title{
5. Considerações finais
}

O naturalismo de Júlio Ribeiro desalojava em bloco uma série de reivindicações do homem (e da literatura) a uma ontologia do sagrado. No contexto específico das batalhas do campo literário no final do século XIX, escritores como Machado de Assis e José Verissimo, apegados a uma concepção clássico-romântica de literatura como discurso nobre e elevado, consideravam a 
intromissão da ciência uma contaminação que degradava e rebaixava a arte da palavra escrita. Ela conspurcava a própria categoria de romance como gênero ficcional. Havia um esforço dos homens de letras para impedir que a literatura fosse "contaminada" pelo discurso científico e pelos gêneros jornalísticos. Além do autor-cientista que respondia pelas explicações técnicas, pelo estudo da histeria e pelos catálogos de objetos, bichos e plantas, havia em $A$ carne um autor-jornalista que enxertava reportagens no romance, assim como uma militância contra o latifúndio paulista e a favor da desanexação da província.

Talvez isso não fosse mais um "romance", mas para o escritor materialista não havia uma categoria sagrada, acima da história, chamada "o romance", da qual os autores se aproximavam ou se afastavam. Em 1866, teorizando sobre os impactos da civilização industrial na literatura, Zola havia ponderado que a palavra "romance" parecia inadequada para descrever a ficção naturalista. Em certo momento, pensou-se em usar a palavra "estudo", mas ela também era vaga e "romance" se manteve (ZOLA, 1995, p. 41). Conceber o romance e o literário como domínios impermeáveis ao discurso científico, à razão, à literatura de jornal e às vulgaridades do corpo mortal - a literatura era o lugar da fantasia, da fabulação e do belo - traía uma concepção idealizada de literatura. Ao passo que, como notou Zola, era a própria categoria de "romance" que entrava em crise com o advento da ficção naturalista.

A batalha de escritores como José Verissimo e Machado de Assis era pela manutenção de uma concepção romântica de arte como hegemônica no campo literário. Tal concepção dava ao autor e à sua obra um ar de mistério e transcendência, ao mesmo tempo dentro e fora da sociedade de consumo. Esse "fora" - que remetia ao sagrado - era reivindicado como algo essencial para a autonomia e sobrevivência do campo literário e de seus agentes, incluindo os editores e os críticos. Nas sociedades em processo de industrialização, nas quais as relações entre os produtores culturais e as classes dominantes passam a ser mediadas pelo mercado, a sacralização da literatura (e do autor) visava apaziguar as incertezas econômicas do empreendimento artístico com ideias sobre a superioridade da arte e o gênio do artista (BOURDIEU, 1996; WILSON, 2000; WOODMANSEE, 1994). 
A posição do consenso crítico em relação ao naturalismo se configura como uma resistência romântica ao materialismo e ao racionalismo, sugerindo que a crítica e a historiografia universalizaram uma concepção de arte de inspiração romântica, própria do início do século XIX. O rompimento do vínculo com o sagrado era visto como um rebaixamento, como a perda daquilo que fazia da literatura um bem de valor, num campo impregnado pelo imaginário romântico da "extraterritorialidade" da arte (MAINGUENEAU, 2006, p. 38). A conclusão lógica da luta pela manutenção da arte no domínio do sagrado foi percebida e assumida por Álvaro Lins quando sustentou que Júlio Ribeiro era "um autor fora da literatura" (LINS, 1963, p. 217). Ele era um autor profano, exilado do templo sagrado da arte. Para a tradição crítica, $A$ carne era uma profanação tanto da literatura em sentido amplo, quanto do romance como gênero. Era um rebaixamento intolerável porque despia os escritores e a literatura de sua excepcionalidade.

\section{Referências bibliográficas}

ANDRADE, Oswald de. Dois emancipados: Júlio Ribeiro e Inglês de Sousa. In: HOLLANDA, A. B. de. O romance brasileiro (de 1752 a 1930). Rio de Janeiro: Ed. O Cruzeiro, 1952, p. 175-178.

ASSIS, Joaquim Maria Machado de. 0 primo Basílio. In: Volume 3. Rio de Janeiro: Editora Nova Aguilar, 1997, p. 903-913.

Obra completa.

BAGULEY, David. Naturalist fiction. The entropic vision. Cambridge: Cambridge University Press, 1990.

BANDEIRA, Manuel. Centenário de Júlio Ribeiro. In: RIBEIRO, Júlio. A carne. São Paulo: Ateliê Editorial, 2002, p. 337-352.

BOSI, Alfredo. História concisa da literatura brasileira. São Paulo: Cultrix, 1972.

BOURDIEU, Pierre. The rules of art. Genesis and structure of the literary field. Trad. Susan Emanuel. Stanford: Stanford University Press, 1996.

BROCA, Brito. Naturalistas, parnasianos e decadistas. Vida literária do realismo ao pré-modernismo. Campinas: Editora Unicamp, 1991.

CAMINHA, Adolfo. Cartas literárias. Fortaleza: UFC Edições, 1999. 
Um livro condenado. A Nova Revista, Rio de Janeiro, n. 2, 1896.

CATHARINA, Pedro Paulo Garcia Ferreira. Quadros literários fin-de-siècle: um estudo de Às avessas, de Joris-Karl Huysmans. Rio de Janeiro: 7Letras, 2005.

EL FAR, Alessandra. Páginas de sensação. Literatura popular e pornográfica no Rio de Janeiro (1870-1924). São Paulo: Cia. das Letras, 2004.

FLAVIO, Alcides. Aluísio Azevedo. In: Rio de Janeiro: Livraria Castilho, 1920, p. 11-19.

Velaturas. Páginas de um velho.

FREITAS, Joaquim José de Sena \& RIBEIRO, Júlio. Uma polêmica célebre. São Paulo: Edições Cultura Brasileira, s.d.

IRMÃO, José Aleixo. Júlio Ribeiro. Sorocaba: Editora Cupolo, s.d.

LINS, Álvaro. Os mortos de sobrecasaca. Ensaios e estudos (1940-1960). Rio de Janeiro: Civilização Brasileira, 1963.

MAINGUENEAU, Dominique. Discurso literário. São Paulo: Contexto, 2006.

MELLO, Maria Tereza Chaves de. A república consentida: cultura democrática e científica do final do Império. Rio de Janeiro: Editora FGV, 2007.

MENDES, Leonardo. Adolfo Caminha e as batalhas pelo reconhecimento literário. Fronteiraz, PUC-SP, vol. 8, p. 1-10, 2012.

O retrato do imperador: negociação, sexualidade e romance naturalista no Brasil. Coleção Memória das Letras, 7. Porto Alegre: EDIPUCRS, 2000.

Zola e o romance experimental no Brasil. In: MELLO, Celina Maria Moreira de \& CATHARINA, Pedro Paulo Garcia Ferreira (org.). Cenas da literatura moderna. Rio de Janeiro: 7Letras, 2010, p. 91-104.

MERQUIOR, José Guilherme. De Anchieta a Euclides. Breve história da literatura brasileira. Rio de Janeiro: José Olympio, 1979.

MONTELLO, Josué. A ficção naturalista. In: COUTINHO, Afrânio (org.). A literatura no Brasil. Rio de Janeiro: José Olympio Editora, 1986, vol. 4, p. 69-90.

PEREIRA, Lucia Miguel. Prosa de ficção (de 1870 a 1920). História da literatura brasileira. Belo Horizonte: Itatiaia, 1988.

PHILLIPS, Adam. Darwin's worms: on life stories and death stories. New York: Basic Books, 2000. 
Freud's helplessness. In: LEVINE, George (ed.). The joy of secularism. Princeton: Princeton University Press, 2011, p. 115-133.

RIBEIRO, Julio. A carne. São Paulo: Ateliê Editorial, 2002.

THÉRENTY, Marie-Éve. La littérature au quotidien: Poétiques journalistiques au XIXe siècle. Paris: Éditions du Seuil, 2007.

VERISSIMO, José. Estudos brasileiros. $1^{a}$. série. Rio de Janeiro: Guarnier, 1901.

Estudos brasileiros. 2ª série. Rio de Janeiro: Laemmert, 1894.

História da literatura brasileira. Rio de Janeiro: José Olympio, 1954.

WILSON, Elizabeth. Bohemians: the glamorous outcasts. New Brunswick: Rutgers University Press, 2000.

WOODMANSEE, Martha. The author, art and the market - rereading the history of aesthetics. New York: Columbia University Press, 1994.

ZOLA, Emile. Do romance: Stendhal, Flaubert e os Goncourt. São Paulo: Edusp, 1995. 
Artigo recebido em: 06 de maio de 2014

Artigo aprovado em: 12 de agosto de 2014

\section{Sobre o autor:}

Leonardo Pinto Mendes é Professor Associado do Departamento de Letras da Faculdade de Formação de Professores e Professor permanente do Programa de Pós-Graduação em Letras do Instituto de Letras da Universidade do Estado do Rio de Janeiro (UERJ). É autor de O retrato do imperador: negociação, sexualidade e romance naturalista no Brasil. Porto Alegre: EDIPUCRS, 2000, e de diversos artigos em periódicos indexados da área, entre os quais os mais recentes: "Virgílio Várzea, escritor naturalista", Revista Soletras (UERJ), jan/jul 2014; "Mulheres de Bronze: Xavier de Montepin e o folhetim no Brasil", Revista escrita (UNIABEU), set/dez 2013; "Vida literária em O Pão da Padaria Espiritual, Fortaleza, 1892-1896", Revista Interfaces (UFRJ), jul/dez 2012; "O crítico Adolfo Caminha e as batalhas pelo reconhecimento literário", Revista Fronteiraz (PUCSP), jan/jul 2012; "Vitor Leal e o romance-folhetim no Rio de Janeiro do final do século XIX", Revista Soletras (UERJ), jul/dez 2011; "Lavadeiros, padeiros e marinheiros: romance brasileira, boemia e homoerotismo na crise do sistema monárquico", Revista Terra Roxa e Outras Terras (UEL), out. 2010. Seu interesse de pesquisa são os gêneros narrativos em prosa no período de 1870 a 1910, e notadamente o naturalismo literário no Brasil, na França e na Inglaterra. 